University of Nebraska - Lincoln

DigitalCommons@University of Nebraska - Lincoln

Faculty Publications, Department of Child, Youth, and Family Studies

Child, Youth, and Family Studies, Department of

2021

\title{
Supporting Children's Healthy Development During Mealtime in Early Childhood Settings
}

Adrien D. Malek-Lasater

Kyong-Ah Kwon

Diane M. Horm

Susan B. Sisson

Dipti Dev

See next page for additional authors

Follow this and additional works at: https://digitalcommons.unl.edu/famconfacpub

Part of the Developmental Psychology Commons, Family, Life Course, and Society Commons, Other Psychology Commons, and the Other Sociology Commons

This Article is brought to you for free and open access by the Child, Youth, and Family Studies, Department of at DigitalCommons@University of Nebraska - Lincoln. It has been accepted for inclusion in Faculty Publications, Department of Child, Youth, and Family Studies by an authorized administrator of DigitalCommons@University of Nebraska - Lincoln. 
Authors

Adrien D. Malek-Lasater, Kyong-Ah Kwon, Diane M. Horm, Susan B. Sisson, Dipti Dev, and Sherri L. Castle 


\title{
Supporting Children's Healthy Development During Mealtime in Early Childhood Settings
}

\author{
Adrien D. Malek-Lasater, ${ }^{1}$ Kyong-Ah Kwon, ${ }^{1}$ \\ Diane M. Horm, ${ }^{1,2}$ Susan B. Sisson, ${ }^{3}$ \\ Dipti A. Dev, ${ }^{4}$ and Sherri L. Castle ${ }^{2}$ \\ 1 Department of Instructional Leadership and Academic Curriculum, The \\ University of Oklahoma-Tulsa, Tulsa, USA \\ 2 The Early Childhood Education Institute at the University of Oklahoma- \\ Tulsa, Tulsa, USA \\ 3 Department of Nutritional Sciences, The University of Oklahoma Health \\ Sciences Center, Oklahoma City, USA \\ 4 Department of Child, Youth, and Family Studies, University of Nebraska- \\ Lincoln, Lincoln, USA \\ Correspondence - Adrien D. Malek-Lasater, adrien.d.malek-1@ou.edu
}

\begin{abstract}
The purpose of this study was to examine the frequency of and relationship between responsive feeding practices used during early childhood education (ECE) mealtimes and high-quality teaching practices and teacher characteristics. We found variation in teachers' use of responsive feeding practices. Teachers were more often observed using role modeling than supporting eating self-regulation. Programs that implemented family style meal service had a generally higher use of responsive feeding practices. Overall, we found positive associations between high-quality teaching practices and responsive feeding practices. Teachers' Head Start status
\end{abstract}

Published in Early Childhood Education Journal (2021)

doi:10.1007/s10643-020-01137-2

Copyright (C) 2021 Springer Nature B.V. Used by permission.

Accepted 16 November 2020; published January 7, 2021 
was associated with teaching practices and role modeling during mealtime. Teachers' education and salary were associated with high-quality teaching practices. This study highlights the possible training needs for teachers related to responsive feeding practices and the need to expand classroom quality assessment to incorporate classroom routines. Finally, this study sheds light on the importance of building better interdisciplinary partnerships to support teachers during mealtimes and to improve ECE mealtime practices in order to help promote optimal outcomes for children in all areas of development.

Keywords: Early childhood education, Mealtimes, Teaching practices, Quality, Responsive feeding practices

Learning and health are inextricably connected, and evidence shows significant inverse relationships between academic success and healthrisk behaviors such as poor dietary intake which can lead to obesity (Bradley and Greene 2013; Michael et al. 2015). The rate of childhood obesity in young children under 5 years of age in the U.S. (13.9\%; Hales et al. 2017) presents a considerable concern for both education and health-related researchers and practitioners since obesity in childhood impedes skills necessary for children's long-term learning, health, and development (Hughes et al. 2015; Riggs et al. 2010). Early childhood education (ECE) programs serve 7.5 million preschool aged children and play an important role in addressing this concern given that these children spend an estimated 30 hours per week (BenjaminNeelon 2018; National Center for Education Statistics [NCES], 2020) and consume at least one half of their daily meals in the ECE settings. Mealtimes offer valuable opportunities not only for shaping children's eating behaviors (Addessi et al. 2005; Gubbels et al. 2010), but also for supporting children's cognitive development and social skills (Hughes et al. 2015; Locchetta et al. 2017).

Despite the influence mealtime has on children's learning and development, a discrepancy in the promotion of high-quality mealtime practices exists between education and health disciplines. For instance, reputable health-promoting organizations such as the American Academy of Nutrition and Dietetics (AND, Benjamin-Neelon 2018) and the American Academy of Pediatrics (AAP 2019) endorse the use of responsive feeding practices by ECE teachers who serve children age 2 to 5 to establish optimal, high-quality feeding environments and promote healthy eating behaviors (Mita et al. 2015; 
Sleet et al. 2019). Responsive feeding practices, however, are rarely promoted by education- related organizations such as the National Association for the Education of the Young Child (NAEYC), a guiding entity that endorses evidenced-based best teaching practices for ECE. It is reasonable to expect that education-promoting and health-promoting organizations have differing priorities, goals, and measures of quality (Hegland et al. 2011). Yet, because recommendations for responsive feeding practices are intended for ECE teachers, there is a need to communicate these recommendations beyond health-promoting experts and researchers. Furthermore, given the implications, the use of responsive feeding practices needs to be incorporated into quality measurements and teaching practices endorsed by education-related entities in order to ensure they are understood and implemented in the classroom. Bridging communication can also allow experts in education to provide insight for health organizations that translates to practical application of mealtime practices and ways to support teachers.

Addressing the concern of childhood obesity and ensuring optimal development of the whole child are complex issues and require the knowledge, ideas, and research from different disciplines. Therefore, optimizing collaboration between disciplines, such as through interdisciplinary research, will lead to more effective solutions. A suggested initial step in interdisciplinary research collaboration is to develop an agreed upon conceptual understanding that will centralize common goals among disciplines (Tobi and Kampen 2018; Tripp and Shortlidge 2019). In terms of ECE mealtime practices, exploring associations between high-quality education and health practices would provide a substantial step in bridging understanding across professional fields. However, there is limited literature examining how high-quality practices identified in early childhood education (i.e., high-quality teaching practices) and health-related disciplines (i.e., responsive feeding practices) are associated with each other and what teacher characteristics contribute to these practices. Thus, the present study examined the responsive feeding practices used during ECE mealtimes and associations with high-quality teaching practices and teacher characteristics. 


\section{Responsive Feeding Practices}

A collection of mealtime practices that support healthy eating behaviors have been deemed Responsive Feeding Practices by researchers and reputable health-promoting organizations such as the AND (Benjamin-Neelon 2018) and the AAP (2019). The recommendations for the use of responsive feeding practices guide ECE teachers to enthusiastically role model eating healthy foods, provide nutrition education and support for trying new foods, allow children to explore food through their senses, and use peer modeling of healthy eating (Greenhalgh et al. 2009; Hendy and Raudenbush 2000) to encourage children to choose and eat healthy foods. Responsive feeding practice recommendations also guide teachers to support eating self-regulation by using verbal prompts to help children to self-serve (Baumeister and Vohs 2004), modeling their own feelings of satiety, and cuing children to sensations that reflect hunger and fullness while supporting their language to express if they are hungry or full (Sigman-Grant et al. 2008). It is important to note ECE teachers serve a variety of children with differing needs and home environments, therefore supporting eating self-regulation in the classroom may require teachers to take an individualized approach. For instance, teachers observing children with low food access and high food insecurity eating voraciously after a weekend at home can provide responsive feeding practices by still teaching and encouraging these children to listen to their internal bodily cues, but may need to give extra reassurance that plenty of food will be available. There are links between food insecurity, poverty, and children's self-regulation (Hails et al. 2019) but much of what is currently understood about supporting children's eating self-regulation is gleaned from studies examining the parent-child relationship (e.g., Scaglioni et al. 2011; Tan and Holub 2011), and more research in this area is still needed to know how teachers can best support children with unique eating needs.

Influential to teachers' use of responsive feeding practices are meal service style and the teacher's feeding style. First, Family Style Meal Service (FSMS) has been identified as one of the styles of high-quality classroom meal service found to support the use of responsive feeding practices (AAP 2019; Benjamin-Neelon 2018). This is because FSMS encourages ECE teachers to sit and eat with children during 
mealtime, enhancing their ability to role model healthy eating while providing nutrition education (Sigman-Grant et al. 2008) and supporting a child's ability to attend to their internal cues of hunger and fullness (Fisher et al. 2003). Not all ECE programs implement FSMS, but many teachers use components from this style of meal service that encourage their use of responsive feeding practices, such as talking with children during meals about the nutritional benefits of food or encouraging children to serve themselves.

Second, ECE teachers' feeding styles, may influence their use of responsive feeding practices. Feeding styles, based on Baumrind's (1971) parenting styles, relate to the amount of demandingness (i.e., healthful eating expectations) and responsiveness (i.e., the extent to which caregivers listen and respond to child's needs and internal cues) provided (Cooper 2020; Maccoby and Martin 1983; Shloim et al. 2015). Authoritative feeding style (high demandingness and high responsiveness) is associated with adequate control over the child's eating and is most compatible with the use of responsive feeding practices (Frankel et al. 2012; Mita et al. 2015; Tovar et al. 2019). Authoritarian feeding style (high demandingness and low responsiveness) is linked to the use of more controlling feeding practices with less attention to a child's internal cues of hunger and fullness (Cooper 2020; Galloway et al. 2006; Loth 2016; Ventura and Birch 2008). Authoritarian feeding style is associated with negative child outcomes such as increased intake of sugary beverages, childhood obesity, and a lowered ability to self-regulate intake. However, some studies have found that authoritarian style has also been associated with a lower weight status in African-American and Latino children (Hughes et al. 2008) and both authoritarian and authoritative feeding style have been associated with healthier weights in children of Chinese immigrants (Pai and Contento 2014). These findings suggest impacts of feeding style may differ based on culture, but more work is needed in this area. Indulgent (low demandingness and high responsiveness) and uninvolved (low demandingness and low responsiveness) feeding styles are permissive feeding styles connected to less structure or monitoring of children's intake (e.g., giving seconds without the child requesting more), and minimal structure including ignoring or being indifferent toward the child, respectively. Studies suggest an association between indulgent feeding styles of parents and higher child weight status (Hughes et 
al. 2011), particularly for children from low-income families (Hughes et al. 2008) and Hispanic boys (Hughes et al. 2011; Olvera and Power 2010). Feeding styles in ECE settings are still being explored and determining the right balance of demandingness and responsiveness needed during mealtimes for children from different populations is still being understood.

Despite their importance, ECE teachers do not always implement responsive feeding practices, and have instead been observed using nonresponsive and controlling verbal strategies that have been shown to override a child's ability to self-regulate food intake (e.g., giving seconds without referencing children's level of satiety, or using rewards or bribes for having a "clean plate", Dev et al. 2016, 2017; Mita et al. 2013; Ramsay et al. 2010; Sigman-Grant et al. 2008). Studies also show teachers are more likely to use certain responsive feeding practices more than others (e.g., using role modeling but not supporting eating self-regulation, Dev et al. 2013; Sleet et al. 2019; Tovar et al. 2019). Currently, studies examining the comprehensive use of responsive feeding practices during ECE mealtimes is underdeveloped, and more studies in this area are needed to know where to better support teacher practices during mealtimes (Swindle et al. 2017; Tovar et al. 2019).

\section{Associations Between Teaching Practices and Feeding Practices}

High-quality teaching practices occur when ECE teachers provide emotional and behavioral support by engaging in interactions that are sensitive and responsive to a child's emotional and academic needs, by fostering a positive climate that supports the building of trusting relationships, and by providing classroom management that maximizes learning time and proactively addresses behavioral concerns. Further, high-quality teaching practices are instructionally supportive in that they contribute to children's higher-level thinking, understanding, and connection to real-world concepts (Burchinal 2018; NAEYC 2009; Pianta et al. 2008). These constructs of emotional, behavioral, and instructional support are frequently assessed by the Classroom Assessment Scoring System (CLASS) which is one validated and widely-used approach for measuring global classroom quality (La Paro et al. 2008). 
Guidelines for high-quality teaching practices offer a model for teachers to provide emotionally supportive interactions and developmentally appropriate instruction that foster children's optimal learning and development (Burchinal 2018; National Association for the Education of the Young Child [NAEYC], 2009). Similarly, responsive feeding practices emphasize positive teacher-child interactions that foster healthy eating behavior and promote a high-quality mealtime. While associations between both types of practices have not yet been examined, there are conceptual similarities. For example, high-quality teaching practices guide teachers to role model positive behaviors, attitudes, and problem-solving skills when teaching (NAEYC 2009). The responsive feeding practice of role modeling also encourages teachers to enthusiastically model eating healthy foods with children and model recognition of their own internal states of hunger and fullness (Benjamin-Neelon 2018; Hendy and Raudenbush 2000). High-quality teaching practices have ECE teachers encourage children's efforts and acknowledge children's comments (NAEYC 2009). In a similar way, responsive feeding practices guide ECE teachers to offer supportive praise when a child chooses healthy foods (Tovar et al. 2019).

Opportunities for emotional, behavioral, and instructional support are understood to be embedded in a variety of contexts and routines in the ECE classroom including mealtime (Booren et al. 2012; Hamre and Pianta 2007). However, studies show a teacher that implements high-quality teaching practices during classroom activities may actually be less engaging or interactive during mealtime (Degotardi 2010; Hallam et al. 2016), and not demonstrate responsive feeding practices during mealtime (Buell et al. 2017). Although mealtimes offer valuable opportunities for learning (Hughes et al. 2015; Locchetta et al. 2017), they are rarely considered in the standard ways used to assess classroom quality or teaching practices (such as the CLASS), and these findings suggest that high ratings in classroom quality assessment may not be translated into high-quality practices that occur during mealtimes. Since high-quality teaching practices are widely known and used in ECE, understanding their relationship with responsive feeding practices could provide a foundation for teachers that clarifies and improves the training for and application of responsive feeding practices in the ECE mealtime, thus providing a good first step in 
laying a foundation for partnerships between ECE- and health-related high-quality practices. Further investigation of associations between these two types of high-quality practices is warranted.

\section{Links Among Teacher Characteristics, Teaching Practices, and Feeding Practices}

Characteristics of ECE teachers serving 2 to 5 -year-olds have been linked to measures of classroom quality. For example, teachers' formal education and training specific to ECE or child development has a significant relationship to their use of supportive social-emotional practices, positive interactions, and provisions for learning (Barnett 2003; Manning et al. 2019; Son et al. 2013). These associations are likely attributed to having a strong knowledge base in child development and effective classroom skills from their educational experiences (National Research Council 2001). In addition, teacher compensation has been associated with a teacher's ability to provide higher quality literacy environments (Barnett 2003), provide activities that promote reasoning skills (St Clair-Christman et al. 2011), and provide Developmentally Appropriate Practices or DAP (Barnett 2003). Further, the quality of teaching strategies may also differ based on attributes of the ECE classroom or program such as Head Start status. Head Start programs are designed to meet the needs of at-risk children and are often associated with significantly higher ratings on classroom quality (Hillemeier et al. 2013). This is likely because Head Start programs are grounded in an evidenced-based, comprehensive, and inclusive learning framework that takes a holistic approach designed to meet the needs of the whole child (U.S. Department of Health and Human Services [USDHHS], 2020). ECE programs who serve a similar population of children but are not Head Start, have been associated with lower measures of quality care and instruction (Hillemeier et al. 2013; Pianta et al. 2002). These associations may be due to these programs not being designed to meet the special needs of children living in poverty, not having as an effective learning framework as Head Start, or may be related to a lack of resources or teacher qualification and training (Hillemeier et al. 2013). 
Although we expect ECE teacher characteristics to be associated with their feeding practices in a way that mirrors associations with high-quality classrooms and teaching practices, only a few studies have explored this possibility. Dev et al. (2014) found lower education level (e.g., less than a college degree) to be associated with more controlling feeding practices. Teacher training specific to child nutrition, feeding, or mealtimes is found to be less prevalent than training specific to child development, which may explain why fostering social skills are emphasized more by teachers during mealtimes than supporting eating behaviors according to Sigman-Grant et al. (2008). Interestingly, Dev et al. (2014) found links between greater nutrition training opportunities and more controlling or non-responsive feeding practices, which was attributed to teachers' concerns about children's food insecurity and obesity. A few studies have found that working in Head Start programs predicted the use of role modeling healthy eating, implementation of FSMS and providing nutrition education (Dev et al. 2013, 2014). The Head Start learning framework includes a component of health, safety, and nutrition that promotes children's development of knowledge and skills for making nutritious food choices and healthy eating habits (USDHHS 2020). Programs are encouraged to use FSMS while using the learning framework to guide curriculum and instruction, therefore teachers are more likely to have the knowledge and training needed to implement responsive feeding practices. However, another study found Head Start staff to use comments thought to be responsive to the child's internal cues only $11 \%$ of the time (Ramsay et al. 2010). Studies have found other characteristics such as when teachers were concerned about a child's weight or were personally trying to lose weight, to be associated with higher use of controlling or non-responsive feeding practices. A recent study by Cooper and Contento (2019) also found characteristics such as teacher's race, years of teaching experience, and whether teachers were also parents to be associated with mealtime practices of sitting and eating with children. Teachers who were white and had less years of experience were less likely to sit and eat with children. Cooper (2020) also found a significant association between years of experience and feeding style, where more teachers used authoritarian feeding styles when they had over five years of experience and more teachers used 
authoritative feeding style when they had less than one year of experience. Teacher compensation and potential associations to responsive feeding practices has not yet been explored in previous studies.

\section{Current Study}

Taken together, there is a need to further examine the comprehensive use of responsive feeding practices to improve understanding on how to offer better targeted support to teachers during mealtimes. There are also conceptual similarities between high-quality teaching practices and responsive feeding practices, yet associations between both of these types of best practices have not been investigated in ECE classrooms. Doing so may build a better bridge between ECE and health disciplines to support training and implementation of responsive feeding practices. Finally, teacher characteristics such as compensation and years of experience have been associated with high-quality teacher practices, but their associations to responsive feeding practices are not fully understood. Thus, this current study sought to examine the frequency of and relationship between responsive feeding practices used during ECE mealtimes and high-quality teaching practices and teacher characteristics. For this study, responsive feeding practices were based on the categories of Role Modeling, Peer Modeling, Sensory Exploration, Pressure Praise Rewards and Threats, SelfRegulation, and Feeding Style (as measured by Mealtime Observation in Childcare [MOCC]; Dev et al. 2020a). High-quality teaching practices were defined as sensitive, responsive, and intentional teaching practices and based on the level of emotional-behavioral support and instructional support provided by the teacher (as measured by Classroom Assessment Scoring System [CLASS Toddler, La Paro et al. 2012 and CLASS Pre-K, La Paro et al. 2008]) outside of the mealtime. Specifically, three research questions were investigated:

1. What is the frequency of the use of responsive feeding practices?

2. Are high-quality teaching practices associated with responsive feeding practices?

3. What teacher and program characteristics are associated with high-quality teaching practices and responsive feeding practices? 


\section{Method}

\section{Participants}

The participants for this study were participating in phase 2 of a larger, interdisciplinary, mixed methods study designed to examine overall teacher well-being (Happy Teacher Project, Kwon et al. 2020). Phase 2 participants were a subsample of 40 infant-toddler and preschool teachers from 10 different ECE centers randomly selected from phase 1 and who agreed to participate in observations including a mealtime observation and classroom quality observation. Of the 40 teachers, seven were excluded from this study due to the age group of children in their classroom (infants and 1-year-olds) not being appropriate for the mealtime observation tool used. As a result, the final subsample for this current study was 31 teachers (18 toddler teachers and 13 preschool teachers) who were racially diverse (6o\% Caucasian, 17\% African American, 10\% Hispanic, 7\% Native American), and had an average of 13.8 years (Range 6 months-30 years) experience teaching in ECE settings. The average age of the participating teachers was 37 years (Range 19-66) and 48\% held a bachelor's degree or higher. Nine of the 31 teachers worked in Early Head Start or Head Start programs.

\section{Procedure}

As part of the Happy Teacher Project (Kwon et al. 2020) teachers provided informed consent and completed a questionnaire reporting their demographic information and educational and work experience backgrounds. Teachers participated in two different classroom observations. One conducted during mealtime and the second during a typical morning without including mealtime. Mealtime observations were conducted by four researchers who were trained and reliable on the MOCC (Dev et al. 2020a). Teachers were observed for mealtime practices during lunch beginning when preparation for the lunchtime began and ending when the last child was finished with lunch and left the table. Classroom observations outside of mealtime were conducted by three researchers certified in using the CLASS (CLASS Toddler, La Paro et al. 2012 and CLASS Pre-K, La Paro et al. 2008) for 
approximately 2 hours during the morning before lunch. Two of the researchers conducted both the CLASS and the MOCC observations.

\section{Measures}

\section{Teacher Demographic Information}

Teachers completed a self-administered questionnaire reporting their demographic information, educational experience, work experience, and classroom information.

\section{Responsive Feeding Practices}

Responsive feeding practices were measured using the Mealtime Observation in Childcare (MOCC; Dev et al. 2020a), which is an observation tool designed to measure ECE teachers' mealtime practices in classrooms serving children between ages 2 to 5 , and was developed by adapting previously validated measures (Hughes et al. 2007; Swin-

dle et al. 2017; Tovar et al. 2019) and the AND best practice feeding domains (Benjamin-Neelon 2018). The MOCC was currently undergoing validation studies (Dev et al. 2020a) and has been revised since our initial data collection. The MOCC version used in this study had 41 questions clustered into 12 subscales plus an area to record characteristics of the meal (e.g., length of meal, number of children and staff present, and foods served). For this study, we used the subscales of Role Modeling, Sensory Exploration, Peer Modeling, Pressure, Praise, Rewards, and Threats, Self-Regulation, and Overall Feeding Style plus items describing meal service and the mealtime environment. Observers were trained to administer the instrument and practiced using the tool until each observer was reliable to the level specified by the tool authors (90-95\% agreement across all subscales among 4 raters).

As suggested by the MOCC authors, most responses were coded as "no, not observed," "yes sometimes (1-2 times)," "yes regularly $\geq 3$," or "unable to observe or not applicable." Responses were converted to a numerical scale ( $\mathrm{O}=$ no, not observed, 1 = yes, sometimes, 2 = yes, regularly $>3$ times). The code "unable to observe" was used if observers could not observe a situation. For example, if no vegetable or fruit was served then the observer could not observe the teacher eating 
vegetables or fruit and the code "unable to observe" was used. However, if vegetables were served and the teacher was not eating vegetables, then the response was "no, not observed." Scores were not penalized for questions marked as "unable to observe or not applicable" therefore the number of items in the subscale with this code was deducted from the total possible points scored (the denominator for the calculation) as to not affect the score. Total points were summed for each subscale and divided by the total possible points for that subscale. Subscale means were then multiplied by 10. Some items were reverse coded in order to reflect the desirable practice with a higher number.

\section{Teaching Practices}

High-quality teaching practices outside of mealtimes, were measured by the Toddler and the Pre-K versions of the Classroom Assessment Scoring System (CLASS Toddler, La Paro et al. 2012 and CLASS PreK, La Paro et al. 2008). The CLASS measures the quality of teacherchild interactions in classroom setting on a 7-point Likert scale (low $=1-2$, mid-range $=3-5$, high $=6-7$ ). The CLASS-Toddler has two domains of Emotional and Behavioral Support (Positive Climate, Negative Climate, Teacher Sensitivity, Regard for Child Perspectives, and Behavior Guidance) and Engaged Support for Learning (Facilitation of Learning and Development, Quality of Feedback, and Language Modeling). High internal consistency ( $\alpha=.92$ for Emotional and Behavioral Support, and $\alpha=.86$ for Engaged Support for Learning) has been reported (e.g., La Paro et al. 2014). The CLASS-Pre-K has three domains of Emotional Support (Positive Climate, Negative Climate, Teacher Sensitivity, and Regard for Student Perspectives), Classroom Organization (Behavior Management, Productivity, and Instructional Learning Formats), and Instructional Support (Concept Development, Quality of Feedback, and Language Modeling). The CLASS Pre-K has been deemed valid and reliable with internal consistency alpha scores for the three domains ranging from .82 to .92 (Downer et al. 2012; Johnson et al. 2017).

As the CLASS-Toddler and the CLASS Pre-K have a different number of domains and dimensions, we reorganized them into two domains: Emotional-Behavioral Support and Instructional Support and used these two subscale scores. Specifically, Emotional-Behavioral Support 
focuses on teacher and child expressions of emotions, the responsiveness and sensitivity of the teacher, and the degree to which children's perspectives are considered and independence is fostered. This composite variable included five dimensions (e.g., positive climate, teacher sensitivity, behavior guidance) from Emotional and Behavioral Support domain in CLASS Toddler and six dimensions (e.g., classroom climate, teacher sensitivity, behavior management/guidance) from Emotional Support and Classroom Organization domains in CLASS PreK. Instructional Support focuses on the ways in which teachers interact with children to facilitate learning activities to effectively support development, learning, and language. This composite variable includes three dimensions (e.g., facilitation of learning and development, language modeling) from CLASS Toddler and three dimensions (e.g., concept development, language modeling) from CLASS PreK.

\section{Results}

The Statistical Package for Social Sciences (SPSS) version 25 was used for all data analysis. Both high-quality teaching practices and responsive feeding practices were analyzed using descriptive statistics, including means and standard deviations of CLASS subscale scores and MOCC subscale scores respectively, with frequencies and percentages of individual MOCC items. Pearson product-moment correlations were used to examine the relationships between the CLASS subscale scores MOCC subscale scores. One-way ANOVA was used to analyze the association between the CLASS subscale scores and overall feeding styles from the MOCC. To examine associations among teacher characteristics, CLASS subscale scores, and MOCC subscale scores, Pearson product-moment correlations were used when analyzing teacher salary, teacher age, and years of teaching, and Spearman's rho correlations (non-parametric) were used when analyzing teacher education level, certification, Head Start status, age group in class, teacher race, and teacher parental status. Associations between feeding styles and teacher characteristics were examined through Chi-Square analysis.

For research question one, we determined the frequency of specific feeding practices within each MOCC subscale (Table 1). The Role Modeling subscale included practices where teachers model healthy 
Table 1 Descriptive statistics on teaching and responsive feeding practices in early childhood settings $(n=31)$

\begin{tabular}{|c|c|c|c|c|c|}
\hline & \multicolumn{3}{|c|}{ Subscale } & \multicolumn{2}{|l|}{ Range } \\
\hline & $\%$ & M & $S D$ & Potential & Actual \\
\hline \multicolumn{6}{|l|}{ Responsive feeding practices } \\
\hline Mealtime environment & & - & - & - & - \\
\hline Children served themselves foods (FSMS) & 45 & & & & \\
\hline Child sized tables/chairs & 94 & & & & \\
\hline Child sized plates/trays & 68 & & & & \\
\hline Child sized serving bowl & 70 & & & & \\
\hline Child sized serving utensils & 83 & & & & \\
\hline Healthy food visuals in classroom & 55 & & & & \\
\hline TV/screen on, visible during mealtime $(R)$ & 23 & & & & \\
\hline Role modeling & & 9.5 & 2.5 & $0-15$ & $5-14$ \\
\hline Sat with children & 77 & & & & \\
\hline Teacher distracted during mealtime & 42 & & & & \\
\hline Ate fast food (R) & 3 & & & & \\
\hline Drank soda/sweet beverage $(R)$ & 10 & & & & \\
\hline Ate fruit/vegetables & $4 / 39$ & & & & \\
\hline \multicolumn{6}{|l|}{ Did not eat meals with children (R) 55} \\
\hline Led pleasant conversation & 84 & & & & \\
\hline Talked about foods served & 87 & & & & \\
\hline Enthusiastically role model healthy eating & 58 & & & & \\
\hline Made negative comments of food served (R) & 16 & & & & \\
\hline Teacher paired food with health benefit & 26 & & & & \\
\hline Showed preference for unhealthy foods (R) & 16 & & & & \\
\hline \multicolumn{2}{|l|}{ Sensory exploration } & 10.5 & 4.4 & $0-20$ & $0-20$ \\
\hline Teacher engaged children's senses & 58 & & & & \\
\hline Teacher discouraged manipulating food & 45 & & & & \\
\hline Verbally encouraged child to try food on plate & 55 & & & & \\
\hline \multicolumn{2}{|l|}{ Peer modeling } & 1.7 & 3.8 & $0-20$ & $0-10$ \\
\hline Prompt peer to encourage child to try food & 17 & & & & \\
\hline \multicolumn{2}{|l|}{ Pressure, Praise, Rewards and Threats } & 10.2 & 2.1 & $0-20$ & $6-16.7$ \\
\hline Provided supportive praise & 55 & & & & \\
\hline Pressured child to eat when they refused $(R)$ & 88 & & & & \\
\hline Extra helping served without child asking (R) & 66 & & & & \\
\hline Used person/judgmental praise $(R)$ & 29 & & & & \\
\hline Praised child for finishing all food $(R)$ & 29 & & & & \\
\hline Promised food reward for eating (R) & 26 & & & & \\
\hline Used praise individualized to behavior & 42 & & & & \\
\hline \multicolumn{2}{|l|}{ Self-regulation } & 7 & 3.2 & $0-20$ & $1.4-15.7$ \\
\hline Talked to child about hunger/fullness & $6 / 13$ & & & & \\
\hline Prevented overserving & 36 & & & & \\
\hline Modeled own feelings of hunger/fullness & 8 & & & & \\
\hline Cued child to feelings of fullness & 13 & & & & \\
\hline \multicolumn{6}{|l|}{ Feeding style } \\
\hline Authoritarian & 9 & & & & \\
\hline Authoritative & 39 & & & & \\
\hline Indulgent & 10 & & & & \\
\hline Uninvolved & 42 & & & & \\
\hline \multicolumn{6}{|l|}{ High-quality teaching practices } \\
\hline Emotional-behavioral support & & 4.3 & 1.5 & $1-7$ & $1.7-6.7$ \\
\hline Instructional support & & 2.6 & 1.3 & $1-7$ & $1-5.1$ \\
\hline
\end{tabular}

(R) refers to feeding practices with reversed scores 
eating behavior and interact with children. Our results showed that while most of the teachers (77\%) sat with the children during mealtimes, only $45 \%$ were observed eating the same foods as the children with about half observed enthusiastically role modeling healthy eating (e.g., eating healthy foods while positively commenting on the food). Most teachers led pleasant conversations with children including talking about foods served (87\%), but rarely discussed health benefits of the food they were eating (26\%). Furthermore, some teachers engaged in behaviors counter to responsive feeding practices such as showing preference for unhealthy foods (16\%) and making negative comments about foods served (16\%). The Peer Modeling subscale included how teachers used children's peers to model trying new foods. Few teachers $(17 \%)$ were observed using a peer model to encourage children to try new foods.

The Pressure Praise Rewards and Threats subscale included items that measure supportive and unsupportive praise, and the use of pressure or rewards to eat. Over half (55\%) of teachers were observed offering supportive praise to children for trying a healthy food option. Some teachers used non-supportive rewards and praise such as using food as a reward for eating or praising children for having a "clean plate". The Self-Regulation subscale included practices that help children recognize and respond to their internal cues of hunger and fullness. About 26\% and $13 \%$ of teachers were observed talking to children about hunger and fullness respectively, and even less (8\%) were observed modeling their own feelings of hunger or fullness. Only 36\% were observed preventing overserving while supporting self-regulation.

For feeding style, most teachers showed either an uninvolved (42\%) or authoritative (39\%) feeding style during mealtime. An analysis of variance (ANOVA) showed that differences in MOCC role modeling subscale scores by the feeding style were significant $F(3,27)=12.44$, $p<.05$. Post-hoc comparisons using the Tamhane's T2 test indicated that MOCC role modeling subscale scores were significantly higher in teachers with an authoritative feeding style $(M=11.45, S D=1.89)$, compared to teachers who had an indulgent and uninvolved feeding style, $(M=7.39, S D=.09, p<.05$ and $M=7.67, S D=1.78, p<.05$, respectively), but there was no significant difference in role modeling scores for teachers using an authoritarian feeding style, $(M=11.31$, $S D=1.33$ ). Other subscales of responsive feeding practices were not significantly associated with teachers' feeding style. 
Table 2 Correlations between high-quality teaching practices and responsive feeding $(n=31)$

\begin{tabular}{lll} 
Responsive feeding practices & \multicolumn{2}{l}{ High-quality teaching practices } \\
\cline { 2 - 3 } & $\begin{array}{l}\text { Emotional-behavioral } \\
\text { support }\end{array}$ & $\begin{array}{l}\text { Instructional } \\
\text { support }\end{array}$ \\
\hline Role modeling & $.59^{* *}$ & $.61^{* *}$ \\
Sensory exploration & .31 & $.37^{*}$ \\
Peer modeling & $.42^{*}$ & .35 \\
Pressure, praise, rewards, and threats & .12 & .10 \\
Self-regulation & $.41^{*}$ & $.39^{*}$ \\
\hline
\end{tabular}

${ }^{* *} p<.01 ;{ }^{*} p<.05$

Descriptives for subscale scores (Table 1) showed teachers had higher scores in Emotional-Behavioral Support than Instructional Support overall. Also, Role Modeling practices were used most often, and those within the Peer Modeling subscale were used least often. Most of the observed classrooms had child-sized furniture and tableware, but only 14 of the 31 teachers (45\%) were observed using FSMS. Eight of these 14 teachers using FSMS were working at Head Start centers where their policy was to use FSMS. Teachers who were at centers that implemented FSMS had overall higher MOCC subscales than teachers who were at centers that used a different form of meal service.

For research question two, we examined associations between highquality teaching practices and responsive feeding practices including feeding styles (Table 2). Emotional behavioral support was positively correlated with mealtime role modeling, peer modeling, and support of self-regulation. Instructional support was positively correlated with role modeling, support of self-regulation and sensory exploration, with a stronger association with role modeling. Analysis of variance (ANOVA) showed that differences in CLASS emotional behavioral support scores and instructional support scores by the feeding style was significant $F(3,27)=7.03, p<.05$ and $F(3,27)=10.75$, $p<$.05, respectively. Post-hoc comparisons using the Tamhane's T2 test indicated CLASS emotional behavioral support scores in teachers with an authoritative feeding style $(M=5.54, S D=1.04)$ were significantly higher compared to those with an indulgent and uninvolved feeding style, $M=3.30, S D=0.30, p<.05$ and $M=3.54, S D=1.44$, $p<.05$, respectively, but no significant difference for teachers using 
Table 3 Correlations of teacher characteristics with teaching practices and responsive feeding practices $(n=31)$

\begin{tabular}{|c|c|c|c|c|c|c|c|c|c|}
\hline Measure & Salary & Age & $\begin{array}{c}\text { Education } \\
\text { level }\end{array}$ & Certified & $\begin{array}{l}\text { Head } \\
\text { Start }\end{array}$ & $\begin{array}{c}\text { Age } \\
\text { group } \\
\text { in class }\end{array}$ & $\begin{array}{l}\text { Years of } \\
\text { teaching }\end{array}$ & Race & $\begin{array}{c}\text { Parental } \\
\text { status }\end{array}$ \\
\hline Role modeling & .31 & .03 & .34 & .17 & $.46^{\star \star}$ & .24 & .00 & -.15 & .17 \\
\hline Sensory exploration & .02 & .09 & .07 & .19 & .25 & -.07 & -.17 & -.12 & .05 \\
\hline Peer modeling & .16 & .16 & $.44^{\star}$ & .21 & .29 & -.23 & .00 & -.16 & .08 \\
\hline Pressure, praise, rewards, and threats & .00 & .34 & .21 & .17 & .23 & .13 & -.01 & -.24 & -.09 \\
\hline Self-regulation & .10 & .22 & .10 & -.03 & .19 & -.11 & -.01 & -.11 & .04 \\
\hline Emotional behavioral support & $.63^{* *}$ & .10 & $.62^{\star *}$ & .08 & $.73^{\star *}$ & .10 & -.02 & -.10 & .20 \\
\hline Instructional support & $.53^{\star \star}$ & $.12^{\star}$ & $.52^{\star \star}$ & -.07 & $.62^{* *}$ & -.00 & .02 & .02 & .29 \\
\hline
\end{tabular}

Spearman's rho correlations (non-parametric) used for teacher education level, certification, Head Start status, age group in class, teacher race, and parental status

${ }^{* *} p<.07 ;{ }^{*} p<.05$

an authoritarian feeding style, $M=3.48, S D=0.76$. Post-hoc comparisons indicated CLASS instructional support scores in teachers with an authoritative feeding style $(M=3.75, S D=1.04)$ were significantly higher compared to those with an authoritarian and uninvolved feeding style, $M=1.97, S D=0.57, p<.05$ and $M=1.83, S D=0.83, p<$ .05, respectively, but no significant difference for teachers using an indulgent feeding style $(M=2.02, S D=0.66)$.

For research question three, we investigated the associations of the teacher characteristics of salary, teacher age, education level, certification, Head Start status (i.e., Head Start or Non-Head Start Teacher), age group served (i.e., Infant-Toddler or Preschool), years of teaching, teacher race, and teacher parental status (i.e., Parent or Non- Parent) with the use of high-quality teaching practices and feeding practices (Table 3). Teacher education, Head Start status, and salary were positively associated with both classroom quality indicators of emotional behavioral support and instructional support. Teacher age, age group served, teacher certification, teacher race, or parental status were not associated with any classroom quality indicators. Teacher education was positively associated with peer modeling. Head Start status was positively associated with mealtime role modeling. Teacher certification, salary, teacher age, age group served, years of teaching, teacher race, or parental status were not associated with any mealtime practice variables. There were no associations among teacher characteristics and feeding styles. 


\section{Discussion}

The purpose of this study was to examine the comprehensive use of responsive feeding practices used during ECE mealtimes and associations with high-quality teaching practices (defined as sensitive, responsive, and intentional practices) and teacher characteristics. This interdisciplinary study contributes to our understanding the conceptual similarities that exist between high quality teaching practices and responsive feeding practices which will help establish a foundation for collaborations between education and health-promoting disciplines (Tobi and Kampen, 2018; Tripp and Shortlidge, 2019). Our study adds to the current body of literature on the quality of the ECE mealtime in two main ways. First, in order to capture the holistic view of recommended responsive feeding practices, we used the MOCC to organize and measure our findings related to feeding practices. Using the MOCC provided us with the structure to measure multifaceted aspects of responsive feeding practices including role modeling, peer modeling, sensory exploration, pressure praise rewards and threats, self-regulation, and feeding style. Second, this is the first study that examined a possible consistency between the quality of teacher practices across classroom contexts (i.e., during the mealtime and outside of the mealtime) and their relations to various teacher and program characteristics.

In our comprehensive examination of responsive feeding practices, we found that although most classrooms provided an appropriate structure to the mealtime environment with child-sized tableware and utensils to allow self-serving and independent eating, the use of responsive feeding practices and feeding styles varied substantially, which is consistent with previous literature (Dev et al. 2013; Sleet et al. 2019; Tovar et al. 2019). The majority of teachers in our study showed strengths in leading conversations during meals, but less often used peer modeling or promoted eating self-regulation during mealtime.

Based on the current literature, one explanation for the varied use of responsive feeding practices could be the use of FSMS (Dev et al. 2016; Erinosho et al. 2012; Ramsay et al. 2010; Swindle et al. 2017). FSMS supports the wide use of responsive feeding practices by guiding teachers to sit and eat with the children, and encouraging children 
to serve themselves, lending to more opportunities for teachers' use of role modeling, peer modeling, and supporting eating self-regulation (Sigman-Grant et al. 2008). Our results support these previous findings as we found teachers from programs that implemented FSMS overall had higher responsive feeding practice subscale scores. However, not all ECE programs are able to implement FSMS since the type of meal service is often dictated by program policies (Dev et al. 2013).

Current literature also points to other potential factors that may help explain the variation in teachers' use of responsive feeding practices. Lack of funding to provide food for teachers during mealtimes can limit ECE teachers' opportunities to role model healthy eating or eating self-regulation (Dev et al. 202ob). Also, teachers' beliefs about children's ability to self-regulate food intake, particularly children from poverty (Hails et al. 2019), can determine whether they trust children to serve themselves enough food or accept children's requests for or refusals of food (Dev et al. 2014, 2017). Our findings were similar and displayed a range of teachers either talking to children about feelings of hunger/ fullness or teachers serving seconds without asking if the children wanted more.

Our findings reinforce the conceptual similarities observed between high-quality teaching practices and responsive feeding practices. Teachers who are able to offer a higher quality of emotional-behavioral support understand the important influence of relationships on a child's development and are likely to role model positive attitudes and behaviors, be sensitive to the child's perspective and emotions, and foster independence (NAEYC 2009). The feeding practices of role modeling, peer modeling, and supporting eating self-regulation that we found to be associated with emotional-behavioral support align with the characteristics of this high-quality teaching practice. Similarly, instructionally supportive teaching practices include best-practices that encourage teacher role modeling, cueing children to solve problems and make decisions, and providing sensory rich environments (Barnett 2003; NAEYC 2009) which are similar to the feeding practices of role modeling, supporting self-regulation, and allowing for sensory exploration during mealtime that we found to be associated with instructional support. Furthermore, authoritative feeding styles were associated with higher scores in both emotional behavioral support and instructional support compared to the other feeding styles, 
which is expected given that the characteristics of an authoritative style aligns most with high-quality teaching practices (NAEYC 2009). Acknowledging associations among teaching and feeding practices is the first step in establishing central interdisciplinary goals that will lead to more effective communication among disciplines for supporting ECE teachers and programs in providing a high-quality mealtime. Further studies that measure high-quality teaching practices and responsive feeding practices simultaneously during mealtime can help deepen our understanding of how these types of practices are related.

Ours is the first study to compare high-quality teaching practices with the recommended responsive feeding practices during mealtime. Variations in measurement or definitions of quality may account for our results being different from other studies that found that teachers with high-quality teaching practices outside of the mealtime were not always as engaged or responsive during mealtime (Degotardi 2010; Hallam et al. 2016). Most of the extant observational tools to assess various aspects of classroom quality, including the CLASS, typically focus on the global quality of teacher practices during instructional or activity settings such as large group, small group, or free play times. The context of daily routines such as mealtimes have rarely been studied as a critical setting for children's learning and development. Our findings suggest teacher practices during mealtime are consistent with and may add to the variations in the global quality that is measured by CLASS. Previous research has suggested (e.g., Hallam et al. 2016) teachers may be less responsive and engaging in routine contexts as they may not see this context as a prime time for children's learning. However, our study observed global classroom quality in connection to the multifaceted use of mealtime practices, which adds to the variations in the global quality measured by CLASS and offer a broader and more holistic approach to assess overall quality of children's experiences in the classroom.

Our findings showed some positive relationships between teacher and program characteristics. Similar to previous literature (Bullard and Hancock 2017; Hillemeier et al. 2013; Son et al. 2013), teachers who are more educated, have higher salaries, and work in Head Start programs are more likely to provide high levels of emotional and behavioral support and instructional support. Similar to findings from Dev et al. (2014) who examined predictors of responsive and 
controlling feeding practices, we found an association between Head Start status and mealtime role modeling. This is likely due to Head Start having a learning framework that supports the whole child (USDHHS 2020) and specific performance standards in place that support responsive feeding practices (Department of Health and Human Services, Administration on Children, Youth, and Families 2016). These findings highlight the important role of teacher education and training on classroom quality, and support the notion that providing trainings about nutrition, healthy eating, and overall interactions with children during mealtime would improve mealtime quality (Sleet et al. 2019). We did not find other associated mealtime practices with Head Start status, which may be related to our small sample size. While our results did not find any association between teacher race and the use of responsive feeding practices or feeding styles, other studies suggest cultural differences may be an influencing factor (Cooper 2020; Cooper and Contento 2019). Both qualitative and quantitative research has been conducted to understand teacher characteristics such as teacher beliefs (Dev et al. 2016) and teacher race (Cooper 2020; Cooper and Contento 2019) in relation to responsive feeding practices, however more research is needed in to better understand these relationships.

Our study had several limitations. First, this study was conducted in one location with a relatively small sample of teachers. A larger sample size would allow for more generalizable results and the use of more advanced statistical analyses. Second, the MOCC is a relatively new tool and was still in the process of development during our data collection. Third, while we examined teacher and program characteristics as potential factors related to global classroom quality and the quality of mealtime practices, there are several factors we were not able to examine in this study. For example, there are other teacher characteristics that may serve as more proximal factors such as teachers' knowledge, attitudes, culture, and training in relation to mealtime practices. Children's characteristics such as race are also necessary to consider when examining the influence of responsive feeding practices in future studies. Also, some centers have policies in place that dictate practices and thus they are not under teachers' control. Given the small sample size, this study was not able to address program-level variations and consider other potential teacher-level factors. It is worthwhile to address this variation in future studies. 


\section{Implications for Research, Practice, and Policy}

The findings of this study hold important implications for research and practice. First, our study highlights the need for more research on mealtimes and teachers' use of feeding practices in order to better understand why some feeding practices such as supporting eating self-regulation and encouraging peer modeling are used less often. More education on responsive and culturally sensitive mealtime practices may be needed in teacher preparation and certification programs or professional development trainings. Second, the relationship between high-quality teaching practices and responsive feeding practices are strong and innovative findings. Through understanding these associations, we can improve ways to better align education and health protocols for ECE mealtime practices that promote healthy eating behaviors that have been shown to reduce child obesity. Third, quality measurements in different classroom contexts, such as using the CLASS during mealtimes, can expand quality assessment to extant high-quality care to incorporate classroom routines. Education and health are linked in a variety of ways (Hegland et al. 2011) and the efforts for supporting optimal child development and health intersect in the ECE classroom. Broadening the lines of communication between researchers and practitioners in both ECE and health disciplines will give ECE directors and teachers accessible and practical guidelines for high-quality mealtimes, as well as offer valuable information to dietitians and other health professionals of what goes on in the classroom. The mutual benefit of having consistency and congruence among all fields that serve young children can provide optimal outcomes in all areas of development.

Author Contributions Each author has made substantial contributions to the conception of this work, analysis and interpretation of data, and revisions to this work. Each author has reviewed and approved the final submission of this work.

Funding This research was funded by the Office of the Vice President for Research at the University of Oklahoma and the Early Childhood Education Institute and the Associate Vice President and Academic Affairs at the University of Oklahoma-Tulsa.

Data Availability The data that has been used in this study is confidential. All participants were assured raw data would remain confidential and would not be shared.

Conflict of interest We have no known conflict of interest to disclose. 


\section{References}

Addessi, E., Galloway, A. T., Visalberghi, E., \& Birch, L. L. (2005). Specific social influences on the acceptance of novel foods in 2-5-year-old children. Appetite, 45(3), 264-271.

American Academy of Pediatrics, American Public Health Association, National Center for Health and Safety in Child Care and Early Education. (2019). Caring for Our Children: National Health and Safety Performance Standards; Guidelines for Early Care and Education Programs, 4th ed. American Academy of Pediatrics. https://nrckids.org/CFOC

Barnett, W. S. (2003). Better teachers, better preschools: Student achievement linked to teacher qualifications. National Institute for Early Education Research [NIEER] Preschool Policy Matters, Issue 2.

Baumeister, R. F., \& Vohs, K. D. (2004). Handbook of self-regulation: Research, theory, and applications. New York: The Guilford Press.

Baumrind, D. (1971). Current patterns of parental authority. Developmental Psychology, 4(1p2), 1-103.

Benjamin-Neelon, S. E. (2018). Position of the academy of nutrition and dietetics: Benchmarks for nutrition in child care. Journal of the Academy of Nutrition and Dietetics, 118(7), 1291-1300.

Booren, L. M., Downer, J. T., \& Vitiello, V. E. (2012). Observations of children's interactions with teachers, peers, and tasks across preschool classroom activity settings. Early Education \& Development, 23(4), 517-538.

Bradley, B. J., \& Greene, A. C. (2013). Do health and education agencies in the United States share responsibility for academic achievement and health? A review of 25 years of evidence about the relationship of adolescents' academic achievement and health behaviors. Journal of Adolescent Health, 52(5), 523-532.

Buell, M., Han, M., \& Vukelich, C. (2017). Factors affecting variance in Classroom Assessment Scoring System scores: Season, context, and classroom composition. Early Child Development and Care, 187(11), 1635-1648.

Bullard, D. J., \& Hancock, L. (2017). Compensation, turnover, and quality. 4.

Burchinal, M. (2018). Measuring early care and education quality. Child Development Perspectives, 12(1), 3-9.

Cooper, C. C. (2020). Tough love or laissez-faire? Exploring the feeding styles of urban preschool teachers and associations with nutrition-focused professional development. Early Childhood Education Journal. https://doi.org/10.1007/ s10643-020-01097-7

Cooper, C. C., \& Contento, I. R. (2019). Urban preschool teachers' nutrition beliefs, mealtime practices, and associations with training. Journal of Nutrition Education and Behavior, 51(9), 1047- 1057. https://doi.org/10.1016/j. jneb.2019.06.006

Degotardi, S. (2010). High-quality interactions with infants: Relationships with early-childhood practitioners' interpretations and qualification levels in play 
and routine contexts. International Journal of Early Years Education, 18(1), 27-41.

Department of Health and Human Services, Administration on Children, Youth, and Families. (2016). Head start program performance standards and other regulations. https://eclkc.ohs.acf.hhs.gov/policy/45-cfr-chap-xiii

Dev, D., Hasnin, S., Sisson, S., Stage, V. C., \& Tovar, A. (2020a). P28 Validation of an observational measure to capture feeding practices in child care centers. Journal of Nutrition Education and Behavior, 52(7), S28-S29.

Dev, D. A., Carraway-Stage, V., Schober, D. J., McBride, B. A., Kok, C. M., \& Ramsay, S. (2017). Implementing the Academy of Nutrition and Dietetics benchmarks for nutrition education for children: Child-care providers' perspectives. Journal of the Academy of Nutrition and Dietetics, 117(12), 1963-1971.e2. https://doi. org/10.1016/j.jand.2017.07.001

Dev, D. A., Garcia, A. S., Dzewaltowski, D. A., Sisson, S., Franzen-Castle, L., Rida, Z., et al. (2020b). Provider reported implementation of nutrition-related practices in childcare centers and family childcare homes in rural and urban Nebraska. Preventive Medicine Reports, 17, 101021. https://doi.org/10.1016/j. pmedr.2019.101021

Dev, D. A., McBride, B. A., Harrison, K., Bost, K., McBride, B., Donovan, S., et al. (2013). Academy of Nutrition and Dietetics benchmarks for nutrition in child care 2011: Are child-care providers across contexts meeting recommendations? Journal of the Academy of Nutrition and Dietetics, 113(10), 1346-1353. https:// doi.org/10.1016/j.jand.2013.05.023

Dev, D. A., McBride, B. A., Speirs, K. E., Blitch, K. A., \& Williams, N. A. (2016). “Great job cleaning your plate today!” Determinants of child-care providers' use of controlling feeding practices: An exploratory examination. Journal of the Academy of Nutrition and Dietetics, 116(11), 1803-1809. https://doi. org/10.1016/j.jand.2016.07.016

Dev, D. A., McBride, B. A., Speirs, K. E., Donovan, S. M., \& Cho, H. K. (2014). Predictors of Head Start and child-care providers' healthful and controlling feeding practices with children aged 2 to 5 years. Journal of the Academy of Nutrition and Dietetics, 114(9), 1396-1403. https://doi.org/10.1016/j. jand.2014.01.006

Downer, J. T., López, M. L., Grimm, K. J., Hamagami, A., Pianta, R. C., \& Howes, C. (2012). Observations of teacher-child interactions in classrooms serving Latinos and dual language learners: Applicability of the Classroom Assessment Scoring System in diverse settings. Early Childhood Research Quarterly, 27(1), 21-32.

Erinosho, T. O., Hales, D. P., McWilliams, C. P., Emunah, J., \& Ward, D. S. (2012). Nutrition policies at child-care centers and impact on role modeling of healthy eating behaviors of caregivers. Journal of the Academy of Nutrition and Dietetics, 112(1), 119-124.

Fisher, J. O., Rolls, B. J., \& Birch, L. L. (2003). Children's bite size and intake of an entree are greater with large portions than with age-appropriate or 
self-selected portions. The American Journal of Clinical Nutrition, 77(5), 1164-1170.

Frankel, L. A., Hughes, S. O., O'Connor, T. M., Power, T. G., Fisher, J. O., \& Hazen, N. L. (2012). Parental influences on children's self-regulation of energy intake: Insights from developmental literature on emotion regulation. Journal of Obesity, 2012, 1-12.

Galloway, A. T., Fiorito, L. M., Francis, L. A., \& Birch, L. L. (2006). 'Finish your soup': Counterproductive effects of pressuring children to eat on intake and affect. Appetite, 46(3), 318-323.

Greenhalgh, J., Dowey, A. J., Horne, P. J., Lowe, C. F., Griffiths, J. H., \& Whitaker, C. J. (2009). Positive- and negative peer modelling effects on young children's consumption of novel blue foods. Appetite, 52(3), 646-652.

Gubbels, J. S., Kremers, S. P. J., Stafleu, A., Dagnelie, P. C., De Vries, N. K., \& Thijs, C. (2010). Child-care environment and dietary intake of 2-and 3-year-old children. Journal of Human Nutrition and Dietetics, 23(1), 97-101.

Hails, K. A., Zhou, Y., \& Shaw, D. S. (2019). The mediating effect of self-regulation in the association between poverty and child weight: A systematic review. Clinical Child and Family Psychology Review, 22(3), 290-315. https://doi. org/10.1007/s10567-019-00279-Z

Hales, C. M., Carroll, M. D., Fryar, C. D., \& Ogden, C. L. (2017). Prevalence of obesity among adults and youth: United States, 2015-2016. National Center for Health Statistics (NCHS). Retrieved from https://www.cdc.gov/nchs/data/ databriefs/db288.pdf

Hallam, R. A., Fouts, H. N., Bargreen, K. N., \& Perkins, K. (2016). Teacher-child interactions during mealtimes: Observations of toddlers in high subsidy child care settings. Early Childhood Education Journal, 44(1), 51-59.

Hamre, B. K., \& Pianta, R. C. (2007). Learning opportunities in preschool and early elementary classrooms. In R. C. Pianta, M. J. Cox, \& K. L. Snow (Eds.), School readiness and the transition to kindergarten in the era of accountability (pp. 49-83). Washington: Paul H. Brookes Publishing.

Hegland, S. M., Aronson, S. S., Isbell, P., Benjamin Neelon, S., Rous, B. S., \& Krajicek, M. J. (2011). Measuring health related aspects of quality in early childhood settings. In M. Zaslow, I. Martinez-Beck, K. Tout, \& T. Halle (Eds.), Quality measurement in early childhood settings (pp. 135-160). Baltimore: Brookes.

Hendy, H. M., \& Raudenbush, B. (2000). Effectiveness of teacher modeling to encourage food acceptance in preschool children. Appetite, 34(1), 61-76.

Hillemeier, M. M., Morgan, P. L., Farkas, G., \& Maczuga, S. A. (2013). Quality disparities in child care for at-risk children: Comparing Head Start and nonHead Start settings. Maternal and Child Health Journal, 17(1), 180-188.

Hughes, S. O., Patrick, H., Power, T. G., Fisher, J. O., Anderson, C. B., \& Nicklas, T. A. (2007). The impact of child care providers' feeding on children's food consumption. Journal of Developmental \& Behavioral Pediatrics, 28(2), 100-107. 
Hughes, S. O., Power, T. G., O’Connor, T. M., \& Fisher, J. O. (2015). Executive functioning, emotion regulation, eating self-regulation, and weight status in low-income preschool children: how do they relate? Appetite, 89, 1-9.

Hughes, S. O., Power, T. G., Papaioannou, M. A., Cross, M. B., Nicklas, T. A., Hall, S. K., et al. (2011). Emotional climate, feeding practices, and feeding styles: An observational analysis of the dinner meal in Head Start families. International Journal of Behavioral Nutrition and Physical Activity, 8(1), 6o. https://doi. org/10.1186/1479-5868-8-6o

Hughes, S. O., Shewchuk, R. M., Baskin, M. L., Nicklas, T. A., \& Qu, H. (2008). Indulgent feeding style and children's weight status in preschool. Journal of Developmental and Behavioral Pediatrics, 29(5), 403-410. https://doi. org/10.1097/DBP.obo13e318182a976

Johnson, S. R., Finlon, K. J., Kobak, R., \& Izard, C. E. (2017). Promoting studentteacher interactions: Exploring a peer coaching model for teachers in a preschool setting. Early Childhood Education Journal, 45(4), 461-470.

Kwon, K.-A., Ford, T. G., Salvatore, A. L., Randall, K., Jeon, L., Malek-Lasater, A., et al. (2020). Neglected elements of a high-quality early childhood workforce: Whole teacher well-being and working conditions. Early Childhood Education Journal. https://doi.org/10.1007/s10643-020-01124-7

La Paro, K. M., Hamre, B. K., \& Pianta, R. C. (2012). Classroom assessment scoring system (CLASS) manual, toddler. Washington: Paul H. Brookes Publishing Company.

La Paro, K. M., Williamson, A. C., \& Hatfield, B. (2014). Assessing quality in toddler classrooms using the CLASS-Toddler and the ITERS-R. Early Education and Development, 25(6), 875-893. https://doi.org/10.1080/10409289.2014.88 3586

Locchetta, B. M., Barton, E. E., \& Kaiser, A. (2017). Using family style dining to increase social interactions in young children. Topics in Early Childhood Special Education, 37(1), 54-64.

Loth, K. A. (2016). Associations between food restriction and pressure-to-eat parenting practices and dietary intake in children: A selective review of the recent literature. Current Nutrition Reports, 5(1), 61-67.

Maccoby, E. E., \& Martin, J. (1983). Socialization in the context of the family: Parent-child interaction. In P. H. Mussen \& E. M. Hetherington (Eds.), Handbook of child psychology: Socialization, personality and social development (Vol. 4, pp. 1-101).

Manning, M., Wong, G. T., Fleming, C. M., \& Garvis, S. (2019). Is teacher qualification associated with the quality of the early childhood education and care environment? A meta-analytic review. Review of Educational Research, 89(3), 370-415.

Michael, S. L., Merlo, C. L., Basch, C. E., Wentzel, K. R., \& Wechsler, H. (2015). Critical connections: Health and academics. Journal of School Health, 85(11), $740-758$. 
Mita, S. C., Gray, S. A., \& Goodell, L. S. (2015). An explanatory framework of teachers' perceptions of a positive mealtime environment in a preschool setting. Appetite, 90, 37-44.

Mita, S. C., Li, E., \& Goodell, L. S. (2013). A qualitative investigation of teachers' information, motivation, and behavioral skills for increasing fruit and vegetable consumption in preschoolers. Journal of Nutrition Education and Behavior, 45(6), 793-799.

National Association for the Education of Young Children (NAEYC). (2009). Developmentally appropriate practice in early childhood programs serving children from birth through age 8: A position statement of the National Association for the Education of Young Children. http://www.naeyc.org/files/ naeyc/file/positions/position\%2ostatement\%20Web.pdf

National Center for Education Statistics (NCES). (2020). Preschool and kindergarten enrollment. https://nces.ed.gov/programs/coe/indicator cfa.asp

National Research Council. (2001). Testing teacher candidates: The role of licensure tests in improving teacher quality. Washington: National Academies Press.

Olvera, N., \& Power, T. G. (2010). Brief report: Parenting styles and obesity in Mexican American children: A longitudinal study. Journal of Pediatric Psychology, 35(3), 243-249. https://doi.org/10.1093/jpeps y/jspo71

Pai, H.-L., \& Contento, I. (2014). Parental perceptions, feeding practices, feeding styles, and level of acculturation of Chinese Americans in relation to their school-age child's weight status. Appetite, 80, 174-182. https://doi. org/10.1016/j.appet.2014.04.029

Pianta, R. C., La Paro, K. M., \& Hamre, B. K. (2008). Classroom assessment scoring system pre-K manual. Baltimore: Paul H. Brookes.

Pianta, R. C., La Paro, K. M., Payne, C., Cox, M. J., \& Bradley, R. (2002). The relation of kindergarten classroom environment to teacher, family, and school characteristics and child outcomes. The Elementary School Journal, 102(3), 225-238.

Ramsay, S. A., Branen, L. J., Fletcher, J., Price, E., Johnson, S. L., \& Sigman-Grant, M. (2010). "Are you done?" Child care providers' verbal communication at mealtimes that reinforce or hinder children's internal cues of hunger and satiation. Journal of Nutrition Education and Behavior, 42(4), 265-270.

Riggs, N. R., Spruijt-Metz, D., Sakuma, K. L., Chou, C. P., \& Pentz, M. A. (2010). Executive cognitive function and food intake in children. Journal of Nutrition Education and Behavior, 42(6), 398-403.

Scaglioni, S., Arrizza, C., Vecchi, F., \& Tedeschi, S. (2011). Determinants of children's eating behavior. The American journal of clinical nutrition, 94(6), S2006-S2011.

Shloim, N., Edelson, L. R., Martin, N., \& Hetherington, M. M. (2015). Parenting styles, feeding styles, feeding practices, and weight status in 4-12 year-old children: A systematic review of the literature. Frontiers in Psychology, 6, 1849 . 
Sigman-Grant, M., Christiansen, E., Branen, L., Fletcher, J., \& Johnson, S. L. (2008). About feeding children: Mealtimes in child-care centers in four Western States. Journal of the American Dietetic Association, 108(2), 340-346.

Sleet, K., Sisson, S. B., Dev, D. A., Love, C., Williams, M. B., \& Hoffman, L. A. (2019). The impact of responsive feeding practice training on teacher feeding behaviors in tribal early care and education: The food resource equity and sustainability for health (FRESH) study. Current Developments in Nutrition, 10, 23-32.

Son, S.-H.C., Kwon, K.-A., Jeon, H.-J., \& Hong, S.-Y. (2013). Head Start classrooms and children's school readiness benefit from teachers' qualifications and ongoing training. Child \& Youth Care Forum, 42(6), 525-553. https://doi. org/10.1007/s10566-013-9213-2

St Clair-Christman, J., Buell, M., \& Gamel-McCormick, M. (2011). Money matters for early education: The relationships among child care quality, teacher characteristics, and subsidy status. Early Childhood Research \& Practice, 13(2), n2.

Swindle, T., Rutledge, J. M., Dix, B., \& Whiteside-Mansell, L. (2017). Table talk: Development of an observational tool to assess verbal feeding communications in early care and education settings. Public Health Nutrition, 2O(16), 2869-2877.

Tan, C. C., \& Holub, S. C. (2011). Children's self-regulation in eating: Associations with inhibitory control and parents' feeding behavior. Journal of Pediatric Psychology, 36(3), 340-345.

Tobi, H., \& Kampen, J. K. (2018). Research design: the methodology for interdisciplinary research framework. Quality \& Quantity, 52(3), 1209-1225.

Tovar, A., Vaughn, A., Fisher, J. O., Benjamin-Neelon, S. E., Burney, R., Webster, K., et al. (2019). Modifying the Environmental Policy Assessment and Observation (EPAO) to better capture feeding practices of family child care home providers. Public Health Nutrition, 22(2), 223-234.

Tripp, B., \& Shortlidge, E. E. (2019). A framework to guide undergraduate education in interdisciplinary science. CBE-Life Sciences Education, 18(2), es3.

United States Department of Health and Human Services [USDHHS]. (2020). Head Start early learning framework. Head Start Early Childhood Learning \& Knowledge Center. https://eclkc.ohs.acf.hhs.gov/school-readiness/article/ head-start-early-learning-outcomes-framework

Ventura, A. K., \& Birch, L. L. (2008). Does parenting affect children's eating and weight status? International Journal of Behavioral Nutrition and Physical Activity, 5(1), 15. 